\title{
Development in Electromagnetism-II
}

\author{
A Review of Some Important Problems, and Laboratory Results
}

By Eugene Bloch, Professor at the Lycée Saint Louis

Concluded from Scientific American Supplement No. 2056, Page 339, May 29, 1915

iJ. ELECTROM AGNETISM AND RADIATION.

THE difficulties just described are not the only ones which the modern theory of electromagnetism encounters. Perhaps the gravest ones arise in adapting it to the experimental facts of radiation. We know that thermal radiation in equilibrium in a constant-temperature chamber, and called "black radiation," has a density independent of the particular body producing it. It is a function only of the wave-length $\lambda$ and the absolute temperature $T$. Our theoretical knowledge of this density, $u \lambda$, is expressed by the well-known laws of Kirchoff, Stefan-Boltzmann, and Wien. ${ }^{24}$ Our experi mental knowledge is expressed by the formula of Planck,

$$
u_{\lambda}=c_{1} \lambda-5\left\{\begin{array}{l}
\frac{c_{2}}{\lambda T} t^{-1}-1 \\
\text { satisfies not only the the }
\end{array}\right.
$$

This equation satisfies not only the three theoretical laws, but also corresponds to the observed distribution of energy in the spectrum of a black body. This formula reduces for large values of $\lambda T$ to the earlier one of Rayleigh,

$$
u_{\lambda}=c_{1} / c_{2} \cdot T / \lambda^{4}
$$

Now, the electromagnetic theory seems to lead almost inevitably to Rayleigh's formula for all wave-lengths in flagrant contradiction to experimental facts. The second formula, indeed, does not give a maximum to the radiation distribution curve and makes the total radiation infinite. This consequence, which the researches of Lord Rayleigh ${ }^{25}$ and Jeans ${ }^{26}$ made extremely probable, has been rendered certain by those of Lorentz. ${ }^{27}$ According to the latter's researches, the most general equation of an electromagnetic system, based upon the ether, electrons, and matter, by a suitable choice of parameters can be reduced to the Hamiltonian form of the equations of mechanics. The application of the method of probability and statistical mechanics, especially the theorem of Liouville (which is a consequence of the Hamiltonian form), leads us, then, to consider as applicable to the ether the theorem of the equipartition plicable to the ether the theorem of the equipartition
of energy which also brings us out with Rayleigh's of energ.

In order to escape from this blind alley and obtain the earlier formula, Planck invented the hyp thesis of the discontinuity of energy or quanta. ${ }^{33}$. According to this hypothesis, the molecular resonators cannot exchange energy with the surrounding medium except in whole multiples of the same elementary quantity (quantum), $h \gamma$, an amount proportional to the frequency of the resonator. The constant $h$ would be a universal the resonator. The constant $h$ would be a universal
constant. We will not explain here the various forms given to the theory by Planck himself, Sommerfeld, Einstein, H. Poincaré, and others (see articles cited, foot-note 27). We will pass over all the consequences which have been deduced from this hypothesis (theory of specific heats by Einstein, etc.), except those which are purely electromagnetic. ${ }^{29}$

It appears that we need not give up for the free ether the equations and ordinary laws of electromagnetics or the dynamics of the free electron. The modification of the electromagnetic theory which we must make, if necessary, relates only to the relations between matter and the ether; that is to say, with regard to electrons not free, to emissions and absorption of energy, or perhaps to emission alone, which must then be considered as discontinuous.

Brillouin $^{30}$ thinks that there is a loophole of escape: Planck's theory rests upon an arbitrary hypothesis with regard to strictly monochromatic resonators having very little physical basis. In giving these up, the complica-

${ }^{24}$ These laws rest only on the Doppler-Fizeau principle, thermodynamical reasoning, and the pressure of radiation,
principles which may be held as well proven if not as experimental fact

${ }^{25}$ Rayleigh, Phil. Mag., vol. 2, p. 539, 1900. ${ }^{26}$ Jeans, l. $c$., vol. 10, p. 91 , 1905 ; vol. 17, p. 229, 1909 ; vol.
17 , p. 773, 1909; vol. 18, p. 209, 1909 .

${ }^{27}$ Lorentz, Revue générale des Sciences, p. 14, 1909; La théorie du rayonnement (The theory of radiation), Rapports
au Congrés de Bruxelles de 1911, publiés par Langevin and de au Congres
Broglie.

${ }^{28}$ See the recent article by J. Perrin in the Revue for No-

${ }^{29}$ These consequences have been resumed in a notable course
of lectures given this year at the College de France by Langevin.

${ }_{30}$ Brillouin, Comptes Rendus, vol. 156, pp. 124, 301, 1913. tion of the reasoning rapidly increases, but Brillouin thinks that we can probably come out with Plancls's formula without recourse to quanta. The result would, however, be inconsistent with the general theory of
Lorentz previously mentioned. Possibly we may hope to reach more precise knowledge of the mechanism of absorption about which we know practically nothing, and thence get a loophole for escape. This doubtless will happen in the future.

There is another domain than that of radiation, wherein the electronic and quanta theories are clearly inconsistent, that of the properties of the metals. According to the electronic theory, the thermal and electrical conductivities of the metals, as well as many other of their properties, are due to the motion of free electrons. We may, indeed, derive thus the law of Wiedemann and Franz. Electrons should therefore play an important part in the specific heats of the metals. But, according to the theory of quanta, the specific heat is uniquely related to the uncharged atomic resonators (Einstein). This accounts for the behavior of the specific heats at low temperatures. But the quanta theory has nothing to offer as to the thermal and electrical conductivities. The discordance is, however, decisive. It is perhaps premature to try to reconcile matters until measures of the thermal conductivities at low temperatures have been made, comparable with the excellent ones on the electrical conductivities made by Kamerlingh Onnes ${ }^{31}$ at the temperature of liquid air and hydrogen.

IV. THE MAGNeton

ur physical propertio have definitely become one of years, and with increasing success, tried to introduce an element of magnetism, the magneton, bringing to bear upon it an imposing mass of experimental results. He started from the theory of dia- and para-magnetism built by Langevin.3 ${ }^{33}$ In that theory diamag. netism is explained by the deformation of the intra atomic electronic trajectories under the influence of an exterior electric field paramagnetism results from the existence of a molecular magnetic moment of certain substances. Weiss has elaborated this theory so as to include ferromagnetism by means of a supplementary hypothesis, that of molecular magnetic fields proportional to the magnetizing force. This idea of an electional to the magnetizing force. This idea of an elec-
tric field is not new. Through it Ritz $\mathbf{z}^{34}$ developed his beautiful theory of the structure of the series of certain spectrum lines and the Zeeman effect. It led Weis to formulie which are well substantiated by experiment not only in the legitimate field of electromagnetism (the rariation of the Curie constant with the temperature), but also as to the specific heats of ferromagnetic bodies It was while looking for such precise experimental confirmation that Weiss was led to the theory of the magneton.

The measure of the absolute value of the atomic magnetic moments of iron and nickel at the temperature of liquid hydrogen, made in collaboration with Kamerling Onnes, led at the start to numbers 12,360 and 3,370 which divided, respectively, by 11 and 3 lead practically which divided, respectively, by 11 and 3 lead practically sponding number was later found to be very close to $0 \times 1,123.5$. For the molecule of magnetite the result were more complex and must be divided by 3 to compare them with the atom of iron. These also led to whole multiples of the same number, the factor of proportionality changing abruptly at certain temperatures as if the atom of iron underwent corresponding alterations. The number 1,235 , of which all the atomic magnetic moments are multiples, will be called the magneton-gramme, and its quotient by the Avogardo num ber (the number of atoms per gramme-atom) is the magneton, $16.4 \times 10^{-22}$. The properties of a ferroma: netic body are then well explained by supposing that the magnetic moments of their atoms are simple multiples of a magneton. Magnetism will then have a granular structure like electricity.

Interesting confirmations have been made of this

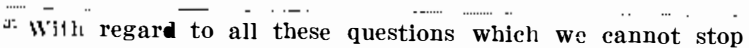
to more than sketch, see the lecture which we delivered before the Societé de physique in December, 1911, upon the electron
theory of metals, and also the book which we have severa theory of metals, and also the book

${ }^{32}$ Weiss, Journal de physique, pp. 900, 905, 1911.

${ }^{32}$ Weiss, Journal de physique, pp. $900,905,1911$.
${ }^{33}$ Langevin, Annales de chimie et de physitute $e_{3}$ vol, 5, p. 70 , st Ritz, Annalen der Physik, vol. 25, p. 660, 1908 theory through measures of various experimenters upon paramagnetic salts or, indeed, upon other bodies. The numbers of Pascal ${ }^{35}$ and those of Mlle. Feytis ${ }^{36}$ are in qualitative and quantitative accord with the hypothesis of the magneton. As these numbers were calculated with reference to water as a standard, an exact knowledge of the diamagnetic constant of water became nec essary. Its measure is difficult and has led to discrepant results. It has been remeasured separately by Séve $^{37}$ and by P. Weiss and Piceard, ${ }^{38}$ who have reache concordant results close to $0.72 \times 10^{-6}$ at 20 eg The theory of the magneton thus has had the merit of fixing definitely this important constant.

We are obliged to admit, however, that for ferromagnetic bodies the atom does not possess a unique magnetic moment, but has a certain number of different values according to the temperature and the chemicil compound into which it enters. All these values, however, have integral ratios. The actual existence of the magneton has been demonstrated in the atoms of iron, nickel, cobalt, manganese, vanadium, calcium, mercury, and uranium. We therefore seem to have here a real, very general constituent element of matter. We may therefore think of adding the magneton to the othe known fundamental elementary bodies. The attempt made by Langevin ${ }^{39}$ to deduce the magneton from the quantum of Planck will doubtless serve as a stimulus in this direction.

IV. 'THE PRODUCTION AND NATURE OF gaseous IONS.

We will not discuss here the simple, ordinary ions such as originate from the X-rays, radium, the Hertz effect, etc. For several years the accepted theory (Langevin, J. J. Thomson, Townsend, and others) was this: the negative electron, torn from a molecule by the ionizing force, surrounds itself with a cortege of neutral molecules; the residual positive atomic ion does likewise. 'Thus originate the ordinary positive - and negative ions. They are characterized by their mobility $K$, coefficient of recombination $a$, and diffusion $D$. At very low pressures and at high temperatures these assemblages are dissociated little by little to the primitive charged center. We will see that some modification of these ideas will be necessary.

(1) Along the line of theory since the fundamental work of Langevin (Annales Ch. Phys., 1905) several new attempts have been made to explain the order of magnitude of the mobilities and their variations. Among these we should specially mention those of sutherland,,$^{40}$ of Wellisch, ${ }^{41}$ and of Reinganum..$^{42}$ Sutherland, especially, departing from the hypothesis of molecular agglomeration, supposes that an ion is identical with the electron or the primitive atom-ion; its velocity is modified and retarded by the electric action exercised upon the neighboring ions or the molecules polarized by its approach. An apparent viscosity is thus created which explains very well the results of I'hillips (see further on) upon the variation of the mobility with the temperature. The actual theory is not unlike that which led Sutherland to his well-known formula for the variation with the temperature of the viscosity of a gas.

It will be perhaps convenient to use the conventions of the older theory, considering the ions as assemblages in perpetual process of formation and disintegration in a kind of dynamical equilibrium; the charged center will then be in turn free and loaded with neutral molecules. We will see that a greater part of the experimental data makes such a convention almost necessary.

(2) With a view to furnishing useful material for the theoretical developments, many measures have been made upon the mobility, the rate of recombination, and the diffusion at various temperatures and pressures. We will mention the measures of Phillips ${ }^{43}$ (variation of $k$ and $a$ with the temperature), Kovorik, ,4, Todd, ${ }^{35}$ Pascal, Ann. Ch. Phys., vol. 16, p. 531, 1909; vol. 19, p. 5 ${ }^{36}$ Mlle. Feytis. Comptes Rendus, vol: :152, p. Tes, 1911. ${ }_{37}$ Séve, Ann. Ch. Phys, vol. 27, p. 189, 1912

${ }^{37}$ Séve, Ann. Ch. Phys., vol. 27, p. $189,1912$.
${ }^{38}$ Weiss and Piccard, Comptes Rendus, vol. 155 , p. 1.234 1912.

${ }^{99}$ Langevin, Rapport a la Conférence de Bruxelles. 1911.

${ }^{40}$ Sutherland, Phil. $M$ ag., vol. 18, p. 341, 1909.

${ }^{41}$ Wellisch, Phil. Trans., vol. 209, p. 249, 1909

${ }^{42}$ Reinganum, Phys. Zeitschr, vol. 12, pp. 575 and 666, 1911

${ }^{43}$ Phillips, Prec. Røy. Søc., 1906, and vol. 83, p. 246, 1910.

44 Kovorik, Physs. Rev., vol. 30 , p. 415,1910 ;. Proc., vol. 86 ,
p. 154,1912 .

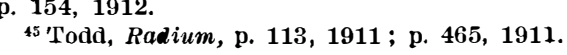


Dempster, ${ }^{46}$ (variation of $\mathrm{K}$ at high and low pressures), Sales $^{47}$ (variation of $\mathrm{D}$ with the pressure). These measures show that ionic agglomerations disintegrate faster at low pressures and high temperatures in the case of
negative ions and tend for both positive and negative ions to revert to the primitive state. This is in accord with the measures made upon flames by Moreau, ${ }^{48}$ Lusby, $^{49}$ H. A. Wilson, and others. ${ }^{50}$ The negative ions Lusby, ${ }^{49} \mathrm{H}$. A. Wilson, and others. ${ }^{50}$ The negative ions
in flames appear to differ little from corpuscles and are in flames appear to differ little from corpuscles and are
scarcely loaded in their accidental encounters with molecules. The positive ion has a size of the order of magnitude of a free atom-ion and often appears to be formed of an hydrogen atom, more rarely of a metallic atom in certain flames colore by salts.

(3) It is mostly with ionization at ordinary temperatures that the newer results have been obtained. The study of ionized gaseous mixtures was first undertaken by Blanc ${ }^{51}$ and by Wellisch. ${ }^{52}$ According to them an ion produce in a gas $A$ and then transported into another gas B, assumes a mobility characteristic of the gas B. This agrees with the idea of temporary agglomerations constantly destroyed and built up again. Blanc carried gas and then transported into air. Wellisch created his gas and then transported into air. Wellisch created his
ions in $\mathrm{CH}_{3} \mathrm{I}$ of $\mathrm{CCl}_{4}$ and then transported them into ions in $\mathrm{CH}_{3} \mathrm{I}$ of $\mathrm{CCl}_{4}$ and then transported them into
hydrogen. According to him the ionization in hydrogen hydrogen. According to him the ionization in hydrogen
is enormously increased by traces of $\mathrm{CH}_{3} \mathrm{I}$, whereas the is enormously increased by traces of $\mathrm{CH}_{3} \mathrm{I}$, whereas the
mobility changes only slightly. It looks as if the heavily ionized molecules of $\mathrm{CH}_{3} \mathrm{I}$ transfer their charges to the hydrogen molecules. This is a remarkable property belonging to certain ions. The same experimenters, as well as Lathey, Tyndall, ${ }^{54}$ and others, have studied with precision the influence of traces of a foreign gas upon the mobility of ions. According to Blanc, a small amount of aqueous vapor diminishes the mobility of the negative ion and increases that of the positive ion in air and in carbonic acid gas (450 and $490 \mathrm{C}$. G. S. for
air instead of 380 and 600 ). The same occurs with alcohol vapor. The molocules of water and alcohol without doubt remain longer associated with the charged nucleus than those of air, carbonic acid gas, or hydrogen. Just the opposite is the case with the molehydrogen. Just the opposite is the case with the mole-
cules of $\mathrm{CH}_{3} \mathrm{I}, \mathrm{CCl}_{4}$, etc. From this we see also that in cules of $\mathrm{CH}_{3} \mathrm{I}, \mathrm{CCl}_{4}$, etc. From this we see also that in
certain gases the positive ions finally surpass the negative ions in mobility. This, for instance, happens with chlorine.

The most remarkable fact in this connection was noted by Franck..$^{55}$ Working upon argon he found normal mobilities (of the order of 1 centimeter in a 1 voltcentimeter field) for the positive ions, while the negacentimeter field) for the positive ions, while the nega-
tive ions had mobilities of more than 200 centimeters and behaved as corpuscles free from corteges of molecules during the major part of their courses in the gas. This enormous mobility diminishes very rapidly under the least trace of oxygen; it is brought down to 1.7 centimeters by 1.5 per cent of oxygen. The tendency to associate with the oxygen molecules is therefore much greater than with the argon atom. Nitrogen shows a behavior analogous to argon.

(4) The study of the charge carried by the ions has led also to important results. The method used for measuring the charge $e$ is base upon the condensation of water-vapor upon the ions (Townsend and J. J. and his pupils. By means of a microscope a single drop of oil or other material charged by the ionized gas is of oil or other material charged by the ionized gas is
observed between the horizontal plates of a condenser. observed between the horizontal plates of a condenser.
Its rates of rise or fall due to the combined electrical and gravitational fields are followed, and from these rates the charge $e$ may be computed. Thus by observing the sudden changes in the rates the new charges can be noted as they are added to or taken away from the drop. It is found that these modifications of the charge of the drop always occur in whole multiples of the same elementary charge, $e$. The mean of the numbers found elementary charge, $e$. The mean of the numbers found
for $e$ was $4.89 \times 10^{-10}$ electrostatic units. This number accords will that deduced by Rutherford from his measures with the rays, although J. Perrin found somewhat smaller values from his study of emulsions and of the Brownian movement.

An important fact was noted by Townsend ${ }^{57}$ and his students: Ions of double charge, $2 e$, or multiples of

${ }_{46}^{46}$ Dempster, Phys. Rev., vol. 34, p. $53,1912$.
${ }_{47}$ Sales, Radium, p. 59, 1911.

${ }^{48}$ Moreau, Comptes Rendus, vol. 148, p. 342, 1909; Radium, p. 70, 1910 .

${ }^{49}$ ILusby, Proc. Cambr., vol. 16, p. 26, 1911; Phill Mag., vol.
22, p. 775, 1911.

${ }^{50}$ H. A. Wilson, Phil. Mag., vol. 21, p. 711, 1911

${ }^{51}$ Blanc, Journal de physique, vol. 7 , p. $838,1908$.
${ }^{62}$ Wellisch, Radium, p. 241, 1909, and 1. c.

${ }^{53}$ Lathey, Prøc. Røy. Søc., vol. 84, p. 173, 1910.
${ }_{54}^{54}$ Tyndall, Nature, vol. 84, p. 530, 1910.

${ }^{65}$ Franck, Verh. Deutsch. Phys. Qesellsch., vol. 12, p. 291, 1910.

${ }^{56}$ Millikan, Radium, p. 345, 1910; Phys. Rev., vol. 32, p. $349,1911$.

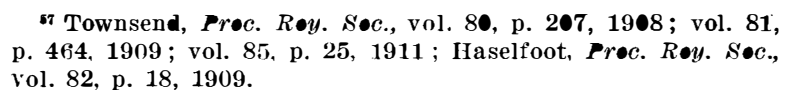

this, were found in ionized gases. This was noted in the experiments made in 1899 , by means of which
Townsend, measuring the diffusion coefficient $D$ by a Townsend, measuring the diffusion coefficient $D$ by a
method using a gaseous current and comparing it with the mobility $k$ was able to determine the product $\mathrm{Ne}$ of the charge of the ion by the Avogadro's number (the number of atoms per atom-gramme). This was a static method and permitted the evaluation directly of the quotient $k / D$ which equals the product $N e$. This result quotient $k / D$ which equals the product $N e$. This result
was dependent upon the method of ionization used. At was dependent upon the method of ionization used. At
mean pressures and with the $a$ rays from radium in air or the secondary rays due to $\mathrm{X}$-rays produced upon polished brass in hydrogen or oxygen, slightly moist, ions of opposite sign were both found to give nearly the value $1.24 \times 10^{10}$. However, if the secondary rays are produced in air at a sheet of brass, oxidized or covere with vaseline, or in other gases (hydrogen, oxygen, car-
bonic acid) upon the same strip polished and covere bonic acid) upon the same strip polished and covered
with vaseline, the value of $\mathrm{Ne}$ is much greater for the with vaseline, the value of $\mathrm{Ne}$ is much greater for the
positive ions. It may be found as high as $2.4 \times 10^{10}$. We conclude therefore first, that certain positive ions carr a charge $2 e$; second, that such ions are produced by the more penetrating secondary rays which are not absorbed by the vaseline. The existence of the polyvalent ions has been confirmed by Franck and Westphal, who returned to the older method, using a gaseous curwho returned to the older method, using a gaseous cur-
rent and devised by Townsend, in which $K$ and $D$ are rent and devised by Townsend, in which $K$ and $D$ are polyvalent ions is about $1 / 10$; with the $a$ rays of polonium or the $\beta$ rays of radium there seem to be $n$ polyvalent ions. Millikan and Fletscher ${ }^{59}$ do not agree with these conclusions, basing their objections upon the method of drops earlier described. But the earlier physicists maintain their interpretation, which also physicists maintain their interpretation, which also
seems to be in good accord with the results from other methods (multiple charges of the a rays from radium, of the canal rays, the positive rays of vacuum tubes, according to J. J. Thomson, Gehrke, and Reichenheim and others)

However, the question must seem at present unsolved. ratio $K / D$ by a new direct method, have concluded vatio $K / D$ by a new direct method, have concluded against the existence of polyvalent ions in the ioniza-
tion by X-rays. We must therefore still leave the question open.

(5) Finally, we must note the remarkable experiment by which C. T. K. Wilson ${ }^{61}$ has enlightened us as to the mechanism of ionization. Continuing his celebrated experiments on the condensation of water vapor on ions, he succeeded in seeing and photographing the trail $\bullet$ ions, produced in a gas by an angle $a$ or $\beta$ particle from ions, produced in a gas by an angle $a$ or $\beta$
radium or a very narrow pencil of X-rays.

His admirable photographs themselves alone can give an idea of all of which we can learn from them. Upo them we see the $a$ and $\beta$ particles following their recionize directly but by the secondary rays which the tear frem the molecules encountered in the gas, etc. We find also a direct verification of the hypothesis advanced by Langevin and put to experimental test by Moulin ${ }^{62}$ in order to explain the "initial recombination" discov ered by Bragg. According to the latter, the saturation current of a gas ionized by a rays is much more diffcult to obtained than when X-rays are used. This is tive atom ions and electrons just liberated, but to a localization of the ions along the path of the $a$ partilocalization of the ions along the path of the a parti-
cles; a saturation current is indeed much easier to cles; a saturation current is indeed much easier to
obtain when the field is perpendicular to the radiation than when parallel.

vi. PHOTOELECTRIC EFFECT.
EFFECTS.)

Light, and especially ultra-violet light, discharges negatively electrified bodies with the production of rays of the same nature as cathode rays. Under certain circumstances it can directly ionize gases. The first of these phenomena was discovere by Hertz and Hallwachs in 1887. The second was announced first by Lenard in 1900. Perhaps on no subject is the literature of the day greater and more contradictory, so we will note only a few of the recent results upon which the bulk of the work has been done.

(1) With regard to the Hertz effect, the researches from the start showed a great complexity of the phenomenon of photoelectric fatigue; that is, the progressive diminution of the effect observed upon fresh me tallic surfaces. According to an important research by Hallwachs, ${ }^{63}$ ozone plays an important part in the

${ }^{58}$ Franck and Westphal, Verh. der Deutsch. Phys. Ges., vol. 11 , pp. 146 and 276,1909

"Millikan and Fletscher, Phys. Rev., vol. 32, p. 239, 1911

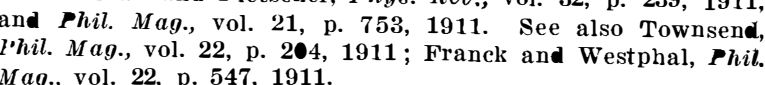
$M a g .$, vol. 22, p. 547, 1911.
${ }_{60}$ Langevin and Salles, S

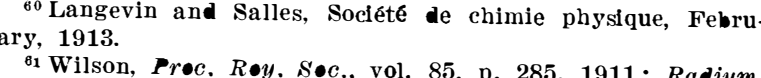
January, 1913

${ }^{62}$ Moulin, Radium, p. 350, 1910.
${ }^{63}$ Hallwachs, Annalen der Physik, vol. 23, p. 459, 1907. phenomenon. However, other elements enter such as oxidation, the humidity, the mode of polish of the surface, etc. We are not even sure that the fatigue is absent in a vacuum. Eugene Bloch $^{64}$ insists that we should work with an exciting radiation of definite wavelength since the fatigue varies from one wave-length to another. He also showe that in certain instances there is an acceleration of the effect which has been refound by various workers.

A great many experiments have been made in a vacuum. Some were undertaken to study the Hertz effect at the rear surface of a strip traversed by the light, an effect perhaps greater there than at the front surface (Stohlmann, Kleemann, and others). Other experimenters have shown a selective effect in the case of certain metals; for instance, with the alkaline metals, according to Pohl and Pringscheim, ${ }^{55}$ there are maxima of exciting power at wave-length $0.300 \mu$ for sodium, at $0.436 \mu$ for potassium, and at $0.390 \mu$ for a liquid alloy of potassium and sodium. The general exciting power increased regularly toward the smaller wave-lengths. Several workers have also endeavored to extend the photoelectric sensitiveness of photoelectric cells into the infra-red (Elster and Geitel) or to utilize them for photophony (Bloch).

However, the greatest effort has been spent in order to find out in vacuum the variation of the initial velocities of the photoelectric electrons with the wave-length. This problem has a great theoretical interest, and the simple laws stated by Lenard since 1900 for the ensemble of radiation emitted should be studied separately for each wave-length of the exciting radiation. According to Lenard, the total number of electrons emitted is proportional to the intensity of the incident light, but their velocity is independent of it, as well as of the wavelength for any given metal. This odd result does not at all agree with the quanta hypothesis which, according to Einstein, leads to a linear variation of the initial energy $m v^{2} / 2$ with the frequency. We may further in our measures replace the initial velocity by the maximum positive potential $V$ which the metal can take under the influence of the rays (that is, the potential of the stoppage of the electrons). The first measures made upon this matter by Ladenburges showed an increase of the initial velocity with the exciting fre quency. Taken up by Ladenburg and Marlav, ${ }^{67}$ Hull, ${ }^{68}$ Hughes, ${ }^{69}$ Richardson, ${ }^{70}$ and others, the experiments have confirmed, although not without dispute and difficulty, the qualitative result of Ladenburg and apparently the theoretical law of variation due to Einstein. Certain writers contest this last deduction and claim a parabolic in place of a linear law of variation. ${ }^{71}$ Our own unpublished experiments completed upon this question lead us to reserve our decision, becauses of the smallness of the ranges of wave-lengths studied by all these experimenters. It will be necessary to take up with quartz apparatus this question, working with the alkaline metals from the visible spectrum way up to the extreme ultra-violet. This is the only procedure whieh will allow a real experimental test of the theory of quanta. We will close with the results obtained by Millikan ${ }^{72}$ and his pupils, who have found in certain cases abnormally high initial velocities. It looks as if there might be some experimental error due to the mode of production of the discharge by the ultra-violet light and the influence of the electric waves from the source upon the measuring apparatus.

(2) The discovery of the ionization of gases by ultraviolet light was made by Lenard in 1900 . As the effect was produced across several centimeters of air and made very great positive and small negative ions, it was natural to interpret the phenomenon, as did J. J. Thomson, as an Hertz effect upon the solid or liquid particles present in the gas. The researches of Langevin and those of Eugene Bloch ${ }^{73}$ have shown, indeed, that the
greater part of the Lenard effect is certainly due to this cause.

The Lenard effect upon the gas itself nevertheless does exist. Refound by J. J. Thomson ${ }^{74}$ and then more decisively by Palmer, ${ }^{75}$ it has already been considerably studied and shows very different characteristics than those at first attributed to it by Lenard. It seems to be produce exclusively by the Schumann or extreme ultraviolet rays of wave-length less than $0.180 \mu$. These rays

${ }^{4}$ Rloch, Radium, vol. 23, p. 125, 1910

12, pp. 215, 349, 1910

'Ladenburg, Phys. Zeitschr., vol. 8, p. 590, 1907.

${ }^{1908}$ es $\mathrm{La}$

${ }^{69}$ Iughes, Phil. Mag., vol. 21, p. 393, 1911; Proc. Cambr

ol. 16. p. 167, 1911.
70 Richardson, Phil. Mag., vol. 24, pp. 570, 575, 1912.

${ }^{7}$ Kuntz, Cornelius, Phys. Review, 1910 and 1913.
$7_{2}$ Millikan and Wright, Phys. Review, January and Febary, 1911

${ }^{73}$ Bloch, Radium, p. 240, 1908 1911. 
will not pass through air, although they will through fluorite and partly through quartz. It produces small ions of both signs, neutral centers, large ions, and azone. It is extremely sensitive to minute traces of impurities in the gas, traces which cannot be detected by other means. It can be distinguished from the Hert effect and become very much greater. All these conclusions are drawn from the researches of Hughes ${ }^{76}$, Can negieter, ${ }^{77}$ Lenard and Ramsauer, ${ }^{78}$, and Leon and Lugene Bloch.79 The latter have shown also that th radiation transmitted by quartz and coming from a mercury arc ionizes the air feebly in the neighborhood oi the arc and seems consequently to emit a smal amount of Schumann rays. In place of the usual source of schumann rays, a hydrogen tube furnished with quartz windows, Lenard and Ramsauer used a ver powerful spark between electrodes of aluminium. The the ionization takes place even through air and quart and the experimenters attribute it to rays of wave length less than $0.1 \mu \mu$, the smallest ultra-violet rays known, and which were discovered by Lymann. As no measure of these wave-lengths was made, it seems as probable that the effect is due to ordinary Schuman rays which have been partially transmitted by media generally opaque to them because of the great origina intensity of the light. This question remains to be studied as well as the Lenard effect in general, the knowledge of which is yet very limited despite the great number of interesting problems connected with it.

\section{The Problem of the High Building}

By Prof. Charles Peck Warren, Assistant Professor of Architecture, Columbia University

The question is frequently asked, Will America eve develop a style of architecture? Probably the nearest we have come to it is in the erection of the skyscraper - the most striking and characteristic feature of Amer can architect

The demand for the skyscraper is an outcome of conditions peculiar to New York, although Chicago claim the honor of having erected the first steel skeleton building. Manhattan Island is so narrow and its trade center is so near one end that the rapid increase in trade since 1870 has necessarily been confined in limited area, and in consed

advanced rapidly in value.

The first direct result of the menace in the height of buildings was the invention of passenger elevators for commercial buildings, for it was soon discovered that tenants would not mount stairs above four, or, at th most, five stories. Elevators were employed for the first time in the Fifth Avenue Hotel in 1856, and later on, in 1868, in the old Equitable Building, destroyed by fire in 1911. The gradual development and improvement in high speed made vertical travel easy and comfortable, and the erection of six, then seven, eight, and finally nine-story buildings became possible. So that the problem of making downtown real estate investments profitable was thus temporarily solved.

As years went on, however, even nine-story building in which the cheapest offices rented for $\$ 2$ per squar foot of floor space ceased to yield sufficient revenue, owing to the constant rise in real estate values, so that the height of buildings had to be raised to ten and twelve stories. It was soon discovered that these tall buildings, constructed as they were of combustible mat rials in the floors, stairs, and elevator wells, could not be controlled in case of tire, so the Building Department in 1882 passed a law requiring buildings exceedin eighty-five feet in height to be fireproof.

This gave a great impetus to steel construction, and buildings such as the Mills, Morse, and Post were erected, in which, for the first time, the floor beams an interior columns were made of iron or steel. Th further development of steel construction made it possible to erect a safe and economical building rising to a greater height.

A new difficulty here presented itself. Under the old system of construction the outer walls became so thick at the base, when the building was carried up twelve or fifteen stories, as to cause a loss of income to the owner, as, on a narrow lot, little more than an entrance hallway would be left. It became necessary to make the walls thinner, and this resulted in the construction of curtain walls and skeleton frames.

The masonry walls are not needed for strength; they are divided into sections and supported by the stee frame. A twelve-story building, for instance, would require 36-inch bearing walls on the first floor, but only 20-inch skeleton walls, saving nearly three feet in th width of the building, or over 10 per cent on a lot 25

${ }^{78}$ Hughes, Proc. Cambr., vol. 15, p. 483, 1910

"Cannegieter, Proc. Amst., p. 1,114, 1911.

${ }_{78}$ Lenard and Ramsauer, Sitzungsber. Heidelberg, 1910-1911. ${ }^{79}$ Leon and Eugene Bloch, Comptes Rendus, vol. 155, pp.
$903,1,076,1912$. feet wide. The walls of the Woolworth Building are 4 feet 4 inches thick at the base. Under
they would have been 10 feet 4 inches.

What is the limit to the height of buildings? The answer is the height at which the building ceases to yield a sufficient income on the investment. There is doubt of the possibility of erecting a building 1,000 feet high-say, seventy-five stories-but would it pay? An examination of the records of the Building Bureau shows that the increase in the height of buildings is not represented by a steady upward line of growth, but by an irregular line in which the upward tendency is interrupted at intervals by lines of depression.

Starting with the year 1890, which marked the beginning of the development of the steel skyscraper, the height rapidly increase to eighteen stories, reached by the Mutual Life Insurance Building in 1892. Then followed a reduction lasting two or three years, and then in upward movement culminating in 1896 in the twenty-four-story Park Row Building. The following decade witnessed a slight repression until about 1900 , and then a rapid turn upward to forty-two stories attained by the Singer Building in 1906. Another ebb followed, and then a rise which was topped in 1912 by the Woolworth Building with its fifty-five stories.

A congestion of skyscrapers in any community is objectionable for several reasons; it is dangerous to life menace to health, and it impedes traffic. It is quite true that the modern building can be made fireproof, but when filled with inflammable material, it becomes, in effect, merely a stove or a furnace in case of fire A large percentage of so-called loft buildings are used for manufacturing purposes, for which they were not designed. Under the present building code it is stil possible for owners to pervert the uses of their buildings. When the new code is adopted the provision requirin a certificate of occupancy to be filed with the plans will operate to prevent this condition.

In regard to the second cause, the dark rooms in which thousands must work, cut off from light and air by the adjoining tall buildings unquestionably have a damaging effect upon the health of the occupants. This, however, might not have any effect in limiting the height of buildings, but the fact that these darkened lower floors yield a smaller revenue will have its effect. Concerning the third cause, it does not need any elaborate explanation to show that tall buildings bring about a thoroughly undesirable congestion of population. Start to walk up Fifth Avenue from Fourteenth Street any day at the noon hour. It is almost impossible, because of the tremendous outpouring of the occupants of the adjoining loft buildings. The result is the neighborhood is shunned, and shops become undesirable, rent falls and the buildings fail to return a proper percentage of profit on the land. When this happens either the building must be torn down and be replaced by a more remunerative one or land values will decrease.

The future uncertainty of land values in New York city will also have a tendency to discourage the erechas been almost uniformly upward but in the last few years there has been in some quarters, notably in the Broadway section above City Hall up and in lower Fifth Avenue, a tendency in the opposite direction Who can foretell with any certainty the effect of the future subways and tunnels upon land values? Suppose the vast outlying area should be developed for manufacturing purposes, of what use would be the lof building?

A skyscraper is not necessarily a money-making investment. The majority return rents less than many other forms of investment, and some of them actually lose money. It is a sad commentary on the life of a skyscraper that the first, the Tower Building, 52 Broadway, erected in 1888, was torn down in 1913 . Why? Because it did not pay, and on its site is being erected a average four-story building.-New york times.

\section{New Instruments of Precision}

THE work of Dr. W. Rosenhain, F.R.S., of the National Physical Laboratory, is very well known to engineers, particularly through his clear and comprehensive reports to the Alloys Research Committee of the Institution of Mechanical Engineers. Besides being a scientist of international repute Dr. Rosenhain is an inventor, and three of his latest instruments are described in his recent Institute of Metals paper on "Some Appliances for Metallographic Research." All three were worke out in the metallurgy department of the $\mathrm{Na}$ tional Physical Laboratory in order to increase the accuracy and convenience of research work of the highest kind. The simplest is a little optical device for the accurate leveling of metal specimens for the microscope. A beam of light, reflected from the polished surface of the metal, is used as an index whereby the surface can be quickly and easily set truly horizontal. The other two instruments deal with problems which arise in the preparation of accurate cooling and heating curves. One of these problems is that of heating and cooling remain constant over a wide range of temperatures. This is attained by the use of vertical tube furnaces so arranged as to be hot at one end and cold at the other, with a uniform gradation of temperature between the two ends. The specimen is raised or lowered in this tube, and is heated or cooled accordingly, the rate being easily varied by altering the rate of raising or lowering. A "blank" heating curve reproduced in the paper shows a maximum variation for 2 deg. Cent. ranging only between 12 seconds and 20 seconds over a temperature range of 700 deg. Cent.

The third appliance described, says the London Daily T'elegraph, is a "plotting chronograph," by means of which the "inverse rate" curves, so freely used in metal lographic research, are plotted automatically to a very large scale, the observer merely tapping a key as the various temperature intervals are passed. The instrument, which thus not only acts as a chronograph, but at once plots the readings in the shape of a curve, is somewhat complex. Its accurate and satisfactory working, however, is testified by the curves with which the paper is illustrated.

\section{SCIENTIFIC AMERICAN SUPPLEMENT \\ Founded 1876}

NEW YORK, SATURDAY, JUNE 5th, 1915

Published weekly by Munn \& Company, Incorporated

Allen Munn, President; Frederick Converse Beach, all at 233 Broadway, New York Entered at Post Office of New York, N. Y., as Second Class Matter
Copyright 1915 by Munn \& Co., Inc.

The Scientific American Publications Scientific American Supplement (established 1876) per year $\$ 5.00$ $\begin{array}{llll}\text { Scientific American (established 1845) } & \ldots & \text { " } & \mathbf{3 . 0 0} \\ \text { American Homes and Gardens } & \ldots & \mathbf{3 0 0}\end{array}$

The combined subscription rates and rates to foreign countries, including Canada, will be furnished upon application

Remit by postal or express money order, bank draft or check
Munn \& Co., Inc., 233 Broadway, New York

The purpose of the Supplement is to publish the more important announcements of distin. guished technologists, to digest significant articles that appear in European publications, and altogether to reflect the most advanced thought in science and industry throughout the world.

Back Numbers of the Scientific American Supplement

SuPPLEM ENTS bearing a date earlier than January 3rd, 1914, can be supplied by the H. W. Wilson Company, 39 Mamaroneck Avenue, White Plains, N. Y. Please order such back numbers from the Wilson Company. Supplements for January 3rd, 1914, and subsequent issues can be supplied at 10 cents each by Munn \& Co., Inc., 233 Broadway, New York.

$W_{E}$ wish to call attention to the fact that we are in a position to render competent services in every branch of patent or trade-mark work. Our staff is composed of mechanical, electrical and chemical experts, thoroughly trained to prepare and prosecute all patent applications, irrespective of the complex nature of the subject matter involved, or of the specialized, technical, r scientific knowledge required therefor.

We also have associates throughout the world, who assist in the prosecution of patent and trade-mark applications filed in all countries foreign to the United States.

Branch Office:

Monn \& Co.,

625 F Street, N. W. Patent Solicitors,

Washington, D. C

New York, N. Y

Table of Contents

Patents and Their Purpose

Nepal.-By Henry John Elwers.-2 illustration

The Combustion of Coal in Boiler Furnaces...

What Carrying on the Great Lakes.-By Day Allen

Utilizing Wastes in Canning Pineaples .................
Atoms and Ions.-VI. -By Sir J. J. Thomson.-2 illustrations

fety in Good Lightin

.

illustrations $\ldots \ldots \ldots \ldots \ldots \ldots \ldots \ldots \ldots \ldots \ldots \ldots \ldots \ldots \ldots$
elopment of Bloch

The Problem of High Buildings.-By Prof. Charles Peck Warre

Wha. . . ............................ 